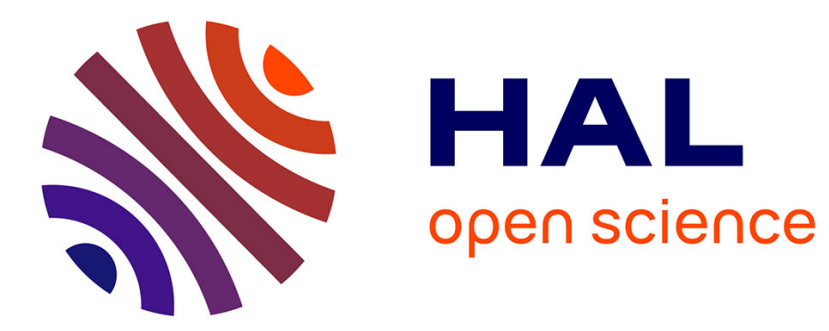

\title{
The microscopic (optical and SEM) examination of dental calculus deposits (DCD). Potential interest in forensic anthropology of a bio-archaeological method
} Philippe Charlier, Isabelle Huynh-Charlier, Olivia Munoz, Michel Billard, Luc Brun, Geoffroy Lorin de La Grandmaison

\section{To cite this version:}

Philippe Charlier, Isabelle Huynh-Charlier, Olivia Munoz, Michel Billard, Luc Brun, et al.. The microscopic (optical and SEM) examination of dental calculus deposits (DCD). Potential interest in forensic anthropology of a bio-archaeological method. Legal Medicine, 2010, 12 (4), pp.163-171. 10.1016/j.legalmed.2010.03.003 . hal-02386898

\section{HAL Id: hal-02386898 https://hal.science/hal-02386898}

Submitted on 1 Oct 2020

HAL is a multi-disciplinary open access archive for the deposit and dissemination of scientific research documents, whether they are published or not. The documents may come from teaching and research institutions in France or abroad, or from public or private research centers.
L'archive ouverte pluridisciplinaire HAL, est destinée au dépôt et à la diffusion de documents scientifiques de niveau recherche, publiés ou non, émanant des établissements d'enseignement et de recherche français ou étrangers, des laboratoires publics ou privés. 


\title{
Author version
}

Charlier P., Huynh-Charlier I., Munoz O., Billard M., Brun L., Lorin de la Grandmaison G. 2010 - The microscopic (optical and SEM) examination of dental calculus deposits (DCD). Potential interest in forensic anthropology of a bioarchaeological method, Legal Medicine, 12: 163-171.

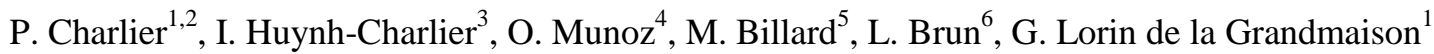

\begin{abstract}
This article describes the potential interest in forensic anthropology of the microscopic analysis of dental calculus deposits (DCD), a calcified residue frequently found on the surface of teeth. Its sampling and analysis seem straightforward and relatively reproducible. Samples came from archaeological material (KHB-1 Ra's al-Khabbah and RH-5 RaOs al-Hamra, two Prehistoric graveyards located in the Sultanate of Oman, dated between the 5th and 4th millennium B.C.; Montenzio Vecchia, an Etruscan-Celtic necropolis from the north of Italy, dated between the 5th and 3rd century B.C.; body rests of Agnès Sorel, French royal mistress died in 1450 A.D.; skeleton of Pierre Hazard, French royal notary from the 15th century A.D.). Samples were studies by direct optical microscope (OM) or scanning electron microscopy (SEM). Many cytological, histological and elemental analyses were possible, producing precious data for the identification of these remains, the reconstitution of their alimentation and occupational habits, and propositions for manner of death.
\end{abstract}

\section{Keywords}

Dental calculus; Forensic anthropology ; Identification Circumstances of death ; Pathological status ; Optical microscopy ; SEM ; Bio-archaeology.

\footnotetext{
1 Department of Forensic Pathology and Medicine, University Hospital R. Poincaré (AP-HP, UVSQ), 92380 Garches, France.

${ }^{2}$ HALMA-IPEL, UMR 8164 CNRS, Lille 3 University, Villeneuve d'Ascq, France.

${ }^{3}$ Department of Radiology, CHU Pitié Salpétrière (AP-HP), Boulevard de l'hôpital, 75013 Paris, France.

${ }^{4}$ UMR 7041, Université de Paris 1, Nanterre, France.

${ }^{5}$ Laboratoire d'Anthropologie Anatomique, Université de Lyon 1, Lyon, France.

${ }^{6}$ Department of Pathology, University Hospital, Parakou, Benin.
} 


\section{Introduction}

The first method of dental calculus microscopic examination was developed in 1987 by Dobney [1]. After being charted and measured on the whole of the teeth, the layers of dental calculus deposits (DCD) were sampled and examined according to various processes after partial decalcification: binocular magnifying glass, optical and electronic microscope (SEM or TEM). It was then possible to identify food remains trapped in the dental plaque and thus preserved: fragments of cereals, vegetable fibers, phytolithes, pollens, seeds, animal hairs, parasites, insects included accidentally, etc. All these elements may bring extra information to the botanical, zoological and parasitological data of the individual or a whole population when all results are compared [2]. The study of dental calculus takes part directly in the appreciation of the framework, alimentation or environment of a subject, but also in the evaluation of its health condition [3].

The electronic microscope allows a much more fine and precise observation thanks to a very large enlargement (bacteria, fungal filaments and viruses may thus be visualized); it may however give only descriptive information not allowing a precise diagnosis for the species present. Nevertheless the methods of molecular biology could be exploited in this case to typify, thanks to the characterization and comparison of their DNA or RNA.

With such observations made on anthropological samples, we would like to show that the microscopic examination of DCD may be particularly helpful for providing decisive data for the identification of a body and the attribution of an identity in a forensic purpose.

\section{Materials and methods}

We submitted several archaeological samples of DCD to a classical optical microscope (OM) and scanning electronic microscope (SEM) analysis in order to try to identify any tissue or, at least, cellular fragments still present in this substance that could be helpful for the determination of the individual habits (with a purpose of identification) and/or pathologies (with a purpose of determination of a manner of death). It consisted in a direct application of microscopic examination coupled with an elemental surface analysis.

The material included nine archaeological samples, four analyzed with an OM and five with a SEM.

Almost all of the skeletons from the Etruscan-Celtic necropolis of Monterenzio Vecchia (=MV; made up of 40 subjects, close to Bologna, Italy; archaeological researches under the authority of Prof. Daniele Vitali and Thierry Lejars) showed variable quantity of dental calculus deposits (Fig. 1a), but, due to conservative reasons, only five of them were sampled (tombs MV 7, MV 15, MV 20, MV 21 and MV 31). These 3-5-mm-long fragments of DCD were sampled directly from the teeth (lingual position of mandibular premolar or molar) during the bioarchaeological survey performed by one of us (P.C.). Evaluation of age at death for these individuals was carried out according to tooth attrition, closing of skull sutures and, when present, importance of osteo-arthritis lesions [4].

They were then cleaned by a fine scraping with non-contaminating plastic instruments and a delicate vaporization of pressured air on all the faces during $10 \mathrm{~min}$. No gold covering was realized in order to be able to perform elemental analysis on the surface. Environmental SEM 
examination of each sample was directly performed on a Philips XL30 CP with X-ray microanalysis (energy-dispersive X-ray spectroscopy). The resolution of the microscope was 3.5 $\mathrm{nm}$ at $30 \mathrm{kV}$ using the secondary electron detector. All images were stored using a standard resolution digital frame store.

A study with optical microscope was also carried out on other samples of DCD taken from:

- A 20 to 25-years-old female skeleton (grave 1, US 169) from the Middle Holocene settlement of KHB-1 at Ra's al-Khabbah (5th to 4th millennium B.C.) in the Sultanate of Oman, excavated by Fabio Cavulli (University of Trento, Italy) in the frame of the Joint Hadd Project, an international archaeological research program directed by Prof. Serge Cleuziou (University of Paris I, France) and Maurizio Tosi (University of Bologna, Italy). Concerning the dental pathologies, we have noticed several lesions of enamel hypoplasia, attesting successive stresses during childhood. The degree of attrition was moderate and calculus present but slight. No carious lesions neither abscesses were recorded [5].

- A 20 to 49-years-old female skeleton (grave 405, individual B) from the Neolithic graveyard of RH-5 at Ra's al-Hamra (4th millennium B.C.) located in the Capital area of the Sultanate of Oman [6], currently excavated by one of us (O.M.), under the authority of the Ministry of Heritage and Culture of Oman and Prof. Maurizio Tosi, and previously excavated by Sandro Salvatori (respectively University of Naples and Centro di Studi e Ricerche Ligabue of Venice, Italy).

- A mandible canine of Agnès Sorel, favorite mistress of the French King Charles VII, buried in the Saint-Ours collegial of Loches (Indre-and-Loire, France) in 1450. Excavation and bioarchaeological analyses were realized by one of us (P.C.). Cause of death was an acute mercury intoxication following the beginning of an anti-helminthic cure. The body was embalmed in Normandy, and then transported to Loches, some $500 \mathrm{~km}$ far away. The dental status was very good [3], with only post-mortem teeth loss due to a recuperation by the local population in order to use them as historical souvenirs or prostheses.

- A maxillary molar of Pierre Hazard (royal notary buried in Maubec, Isère, France) in the $15^{\text {th }}$ century. Macroscopic bio-archaeological analyses were realized by one of us (M.B.). His body was embalmed with lime after an opening of the body and a complete extraction of all organs. Dental calculus and moderate alveolar attrition were observed.

The methodology employed for the sampling and preparation of DCD was in all points comparable with that of putrefaction fluid deposits (PFD), previously published by our research team [7]:

- The first step consisted in a very fine fragmentation of the sample. This was justified by the fact that DCD has no architecture of its own and that this fragmentation does not consist in a loss of information (since we worked in a microscopic scale). In addition, this reduction allowed for a better penetration of the fixative substances.

- In order to rehydrate and fix the samples, they were immersed in $20 \%$ diluted acetic acid for $48 \mathrm{~h}$, in order to slowly decalcify the fragments of DCD.

- Our solution was obtained using the following two phases: a liquid phase made of the DCD in suspension and a solid-phase slope. These two phases have been studied separately.

- The cytological analysis of the DCD in suspension began with the sampling of $200 \mathrm{lL}$ from the supernatant. This liquid was then centrifuged (800 turns per minute for $10 \mathrm{~min}$ ) in order to obtain two spots per slide. Four slides were produced by sample: two slides were colored by the technique of Papanicolaou after a fixing of the spots with a lacquer; the two other blades were colored by the technique of the May-Grünwald-Giemsa (MGG) after fixing of the spots to the air. 
- The study of the remaining solid phase (base of centrifugation) was carried out after a new centrifugation (3500 turns per minute for $10 \mathrm{~min}$ ). The supernatant was kept in reserve (for a later possible cytological study) while the base was recuperated then fixed $24 \mathrm{~h}$ in the AFA (acetic acid, formaldehyde and alcohol). Soon after fixation and decalcification, the sample was put in cassette on a foam, followed by the traditional circuit of inclusion (dehydratation in xylene and increasing alcohol baths, then inclusion in liquid paraffin, cooling, section with the microtome (from 6 to $10 \mathrm{~lm}$ ), deposit on an albumenized slide, air-drying free, dewaxing and rehydratation by immersion in xylene then in increasing alcohol baths to distilled water). Four colorations were carried out for each sample: periodic acid Schiff (PAS), Gram, toluidine blue and hematoxylineosin-saffron (HES).

\section{Results}

\subsection{KHB-1 (grave 1, US 169)}

A total of three fragments of 1-mm length from the lingual face of a mandibular molar were studied one by one with OM. In all cases, numerous vegetal structures have been observed, associated with degraded Malpighian epithelial cells (Fig. 1b and c). Some fungal filaments and rare crystals were also seen.

\section{2. $\mathrm{RH}-5$ (grave 405, individual B)}

Were sampled two fragments of 1- and 3-mm length from the lingual face of a mandibular molar, secondary studied one by one with OM. In both samples, many crystals were observed (Fig. 1d) accompanied by particularly numerous vegetable fibers (Fig. 1e).

\subsection{Monterenzio Vecchia 7 (MV 7)}

Two fragments of 2- and 3-mm length were studied successively with the SEM. The elemental analysis of the matrix showed in both samples a composition rich in phosphorus, calcium and oxygen (calcium phosphate). Within this matrix, crystals made up of silicon and oxygen was observed in great number, with a hexagonal characteristic form (quartz crystals: Fig. 1f). Lastly, some fungal filaments and spores were highlighted (Fig. 1g).

\subsection{Monterenzio Vecchia 15 (MV 15)}

An important fragment of 4-mm length was examined with the SEM. The elemental analysis of the matrix, which appeared as a fibrillar accumulation (Fig. 2a) sometimes grinding the surface of dental enamel (Fig. 2b), highlighted a phospho-calcium nature (Fig. 3) with some crystals of quartz and alumino-silicate. More in-depth, towards dental enamel, many filamentous elements of vegetable origin broad from 5 to $7 \mathrm{~lm}$, enchased in the anfractuosities dug in the matrix have been observed (Fig. 2c-e). Elemental analyses of these formations (vegetable hairs rather than fungal filaments?) showed a complete phospho-calcium mineralization.

\subsection{Monterenzio Vecchia 20 (MV 20)}

A total of three samples of 2-mm length were observed with the SEM. The elemental analysis of the matrix showed in all samples a composition rich in phosphorus, calcium and oxygen comparable that of the individuals MV 7 and MV 15 (calcium phosphate). Within this matrix, quartz crystals were observed whose composition was confirmed by the elemental examination. 
In some places, irregular formations from 50 to $70 \mathrm{~lm}$ length (Fig. 2f) have been seen, whose elemental analysis showed a very great high content in manganese.

\subsection{Monterenzio Vecchia 21 (MV 21)}

The study with the SEM of two samples of 3-mm length showed in both cases an aluminosilicate matrix comparable with that of the individual MV 31. Within this matrix, some crystals were observed, of comparable composition (Fig. 4a). Lastly, many fungal filaments were present on the sectional surface, in close contact with enamel or in the thickness of the dental layers of sediment, carrying out true tunnels within the calcified matrix (Fig. 4b-e).

\subsection{Monterenzio Vecchia 31 (MV 31)}

The study with the SEM of four samples of 1-mm length showed in all cases the existence of several foreign bodies wedged in the matrix: vegetable fibers, red blood cells, grains of starch. On the surface, fungal filaments were observed. An elemental analysis of the matrix showed that prevalence of silicon clearly predominated with relative high levels of calcium and magnesium (Fig. 5). Taking into account of the strong oxygen and aluminum rates, matrix seemed to be composed of alumino-silicate. Carbonaceous, magnesium and sulfur impurities were finally found, but also some quartz crystals, whose nature was confirmed by the elemental study (Fig. 4f).

\subsection{SEM control sample}

A 1-mm length fragment of spongy bone (diploe from the skull of the individual MV 21) was examined with the SEM in order to check elemental proportioning. The Haversian structure of the bone was confirmed with the microscopic examination associated with the elemental analysis, as well as the hydroxy-apatite composition of the osseous spans (high content in calcium, phosphorus and oxygen: $\mathrm{Ca} 10(\mathrm{PO} 4) 6(\mathrm{OH}) 2$ in chemical formula).

\subsection{Agnès Sorel}

Many structures were highlighted, in particular food remains such as vegetal fiber with full refringence conservation under polarized light (Fig. 6a). Some Malpighian cells were also observed, coming from the mouth mucosa (Fig. 6b) and one bacteria of spirochete type particularly visible after a coloration of Gram (Fig. 6c) whose precise characterization was impossible to give (very likely Treponema denticola, a cultivable anaerobia saprophyte bacteria of dental calculus).

\subsection{Pierre Hazard}

Vegetal fibers (comparable to those of KHB-1) were seen (Fig. 6d), accompanied by crystals and Malpighian epithelial cells (Fig. 6e).

\section{Discussion}

\subsection{Background}

The whole of the oral cavity is covered by a translucent film composed of salivary glycoproteins, being able to reach several millimeters thickness. During the intra-uterine life, the oral 
cavity is sterile, but at the time of the passage of the pelvi-genital area, a bacterial colonization occurs, amplified by the first times of milk alimentation (contamination by the skin surface of the breast). This layer also sticks to the surface of the teeth, especially on the irregularities of the surface. An accumulation of Gram-negative and anaerobic bacteria takes place, of yellowish color, extremely sticky, that is called "bacterial plaque" (or "dental plaque"). Its development, supra- or sub-gingival, arises in three phases: on the physiological preexistent film, some bacteria adhere then proliferate and form colonies, i.e. aggregation of filamentous organizations and spirochetes [8]. Also amalgamate with this substance some fragmentary food remains and cells from the mouth mucosa that are incompletely altered by digestive enzymes and/or bacterial proteases; these elements calcify progressively in the dental plaque, this calcification permitting thus differential diagnosis with external contamination after death or sampling [9].

Composed of around 100 billion bacteria per gram, the dental plaque may calcify and form the "dental calculus" or "dental tartar". This calcification is not exactly complete, because some sectors remain non-mineralized in the form of channels or gaps still comprising in their centre an important aerobic and anaerobic bacterial colony [10]. Another type of formation of dental calculus is a spontaneous calcium salt precipitation on the surface of the teeth; in this case, deposits are present especially at the openings of the excretion channels of salivary glands (lingual faces of the mandible incisors and vestibular faces of the maxillary molars). Many microbial and fungal species were found in this kind of deposit [11]: Actinomycetes (Actinomyces israeli and A. naeslundii mainly), Veillonellae, bacteroides, fusobacteries, not identified Gram-positive bacilli, etc.

The elemental analysis of dental calculus also showed its extreme diversity of composition [12]. Four major elements were identified: calcium and phosphorus (mainly), magnesium (up to $3 \%$ of the mass), zinc (up to $1 \%$ of the mass). Other minor elements were only found as traces: titanium, nickel, cobalt, arsenic, strontium, zirconium, cadmium, selenium and lead. The following inorganic molecules were also identified [13]: brushite, di-hydrate phosphate dicalcium, phosphate octo-calcic, hydroxyapatite, whitlockite. The variation of composition of the dental calculus is extremely important between individuals [14]. Factors that are potentially involved in this important variability are [15]: food, salivary $\mathrm{pH}$, oral hygiene, the immunizing state of the subject, environment, oral anatomy of the individual, salivary flow, masticatory disorders, ethnic origin, age of the subject, etc. Lastly, dental calculus has been accused in the development of periodontal diseases, i.e. the irritating and inflammatory diseases concerning the support tissue of the tooth [16-17].

\subsection{Precedent studies on dental calculus from skeletal remains}

Very early, the anthropological interest of dental calculus has been recognized. A simple methodology was developed, initially allowing the extraction of phytolithes from dental calculus deposits of prehistoric herbivores. Its preparation from a skeletal human sample is particularly easy [18]:

- Two washings of the taking away with distilled water allowing the elimination of a possible postmortem contamination;

- A final superficial washing with diluted hydrochloric acid;

- A direct examination with optical microscopy.

Dental calculus was described on bones of Portuguese Middle Pleistocene [19], but Vandermeersch was the first, in 1994, to use the electron microscope (SEM) to identify micro- 
organisms directly involved in the development of the dental plaque [20] on an individual of the Middle Paleolithic discovered on the site of Kebara, Israel.

A microbiological study carried out on skeletons dated between 500,000 to 12,000 years B.C. from Chile, Spain and Near East showed the rather frequent presence of Streptococcus mutans in dental calculus.

Nevertheless, it seems that the distribution of this bacterial species was related neither to the food mode, nor to the conditions of life [21]; this observation is opposed to that of a Mesolithic bone collection from Yugoslavia that showed sex differences of calculus and dental wear distribution revealing different food modes [22]. Dental calculus was found particularly frequent in a population of the Bronze Age (2000 years B.C.) in Bahrain [23] and in a population of breeder-farmer-fishermen of Umm an-Nar (Abu-Dhabi) [24]; within a collection of almost 11,000 teeth coming from Harappa (Pakistan), a contemporary site, 6.8\% of the teeth were decayed with almost generalized layers of calculus deposits [25]. The systematic odontological study of 12 skeletal collections dated from the Bronze Age (3000 years B.C.) to the $16^{\text {th }}$ century A.D. coming from the Arabian Gulf [26], was the occasion to work out a classification of pathological odontological characteristics:

- Marine mode (severe dental wear, weak frequency of decays, dental abscesses caused by dental wear, weak ante-mortem dental loss);

- Pastoral, marine and agrarian mode mixed (moderate dental wear, moderated dental calculus, low level of decays, low level of dental abscesses caused by dental wear, weak rate of antemortem dental losses);

- Agro-pastoral mixed mode (weak and moderate dental wear, important frequency of decays, dental calculus, abscesses caused by dental wear, severe dental ante-mortem losses);

- Mode of intensive agriculture (severe dental wear).

The anthropological study of a dental sample from Monte Bibele (Etruscan-Celtic necropolis of the north of Italy, close to Bologna and Monterenzio Vecchia) showed the frequent presence of dental calculus [27] that indicated, for the authors, a large extent of proteins in the alimentation of the population. The great frequency of ante-mortem dental losses and dental abscesses was in agreement with the importance of decays and calculus. The microscopic observation of enamel surfaces showed the presence of an important share of plants in the food. The analysis of the whole of the dental characteristics made it possible to conclude that this population had an economy with agrarian prevalence.

The examination of two skeletal collections coming from late medieval Serb cemeteries showed many dental anomalies: important dental wear, severe alveolar attrition, frequent decays and generalized dental calculus. Such anomalies were reported as secondary to an abrasive food mode and a deplorable oral hygiene [28]. Lastly, dental calculus of 20 Hungarian mummies dated between the 18th and 19th century A.D. were studied with optical and electronic microscope, and under polarized light. Positive Gram bacteria were identified within all the preparations, while negative Gram bacteria were present in only 12 subjects, and fungal filaments in only three individuals. Flesh-colored food remains were visible in five individuals, and vegetable fragments in the totality of the individuals. Non-organic elements and cellular remains could be identified within all the preparations [29].

\subsection{Comparative analysis of our results}

4.3.1. KHB-1 (grave 1, US 169) and RH-5 (grave 405, individual B) 
In these populations of fish-eaters, the numerous vegetal structures observed may be of diverse origins: food (herbs, vegetables), fibers from the fishnet when restored, or from the basket and rope work, using the mouth as a third hand (such activities are attested at RH-5 by mineralized mat and rope remains). The extreme wear on the lower central incisors of the subject from $\mathrm{RH}-5$, associated with the ante-mortem loss of both superior first premolars as well as interproximal grooves occurring as symmetrical transverse furrows worn into the mesial or distal surfaces of the teeth, could be the consequences of such a use of the mouth (Fig. 6f). Degraded Malpighian epithelial cells very likely originate from the mouth mucosa.

The presence of crystals may lastly be explicated by the desert and/or beach sand transported by the wind to the aliments, the grit involuntarily assimilated with dried fish [30], or by the fragmentation of the grinding stone with pulverization of crystal fragments into the food [31]. These particles could explain the important and premature abrasion of dental enamel surface for the young age of one of the subjects (KHB-1, grave 1, US 169).

\subsubsection{Monterenzio Vecchia (MV 7, MV 15, MV 20, MV 21, MV 31)}

Vegetal fragments were found in all the samples, confirming the importance of this alimentation for this population. Unfortunately, their extreme fragmentation did not allow us a precise identification of the species present. They were accompanied by some crystals (quartz or alumino-silicate) originating from the fragmentation of grinding stone, due to the geographical localization of the site (Apennines, central part of north Italy, close to Firenze and Bologna), responsible for an important and premature dental wear in this population.

For the individual MV 20, the elemental analysis of some crystals showed a very high content in manganese, an element frequently found in ancient ceramics paintings: a food (vessel) or work-related (ceramist or painter) origin of this compound was thus very probable. The nature of this kind of crystal gave then pertinent information about the habits of this individual (type of alimentation vessel, work exposure to pollutant, etc.).

The matrix composition was variable between the five individuals sampled of Monterenzio Vecchia: alumino-silicate at some, phospho-calcium at others (Table 1). More, it is important to note that the opposition between MV 7, MV 15 and MV 20 on one hand, and MV 21 and MV 31 on the other hand, confirmed the existence of two different groups in the necropolis according to the topographical repartition of anthropological variations [4] (olecranial perforation, Patella emarginata, supernumerary bones on the skull vault, enamel hypoplasia). These groups may have been founded on familial, ethnic or status differences, with variations, for example, in the alimentation process and/or composition of saliva.

\section{Conclusion}

The whole of the analyses provided important information on the food, environmental habits, work-related intoxication of the skeletonized individuals with possibilities of familial or social group differentiation.

As for the microscopic examination of PFD [7], some interesting data may be obtained pending some precautions, particularly by carrying out an examination and elemental analysis of the adjacent sediment in order to check if the recorded values testify to an external contamination or one from the original source. 
SEM examination may be made without any preparation and authorizes a complete preservation of the sample; observation of biological and mineral structures is then possible (red blood cells, vegetal fibers, crystals, etc.) with the possibility of elemental surface analysis. Optical microscopy examination of DCD is destructive but may supports direct diagnoses and complementary analyses as such as immuno-cyto-chemistry or DNA extraction; more the examination of red blood cells offers the opportunity of intra-cytoplasmic elements diagnosis such as parasites (Plasmodium sp., for example, in a context of malaria [32]) or metals (gold, for example, in a context of chronic poisoning [33]).

\section{Conflict of interest}

The authors have declared no conflict of interest.

\section{Acknowledgments}

The authors would like to thank warmly V. Mazel and P. Richardin for the MEB analyses carried out in their laboratory (C2RMF, Louvre Museum), and the anonymous reviewers for their important comments and modifications proposed for our text.

\section{References}

[1] Dobney K, Brothwell DR. A method for evaluating the amount of dental calculus on teeth from archaeological sites. J Archaeol Sci 1987 ; 4(14): 343-51.

[2] Juan-Tresserras J, Lalueza C, Albert RM, Calvo M. Identification of phytoliths from prehistoric dental remains from the Iberian Peninsula and the Balearic Islands Madrid: Centro de Ciencas Medioambientales. CSIC, Monografias 1997; 4: 197-204.

[3] Charlier P. Les dents d'Agnès Sorel. Inf Dentaire 2005;25(87): 1512-3.

[4] Charlier P, 2005. Ostéo-archéologie de deux necropolis étrusco-celtiques: Monte Bibele et Monterenzio Vecchia (Bologne, Italie). Reconstitution d'une pathocénose à l'échelle de la vallée de l'Idice. Thesis Paris, France: EPHE, IVème Section, Sciences Historiques et Philologiques, La Sorbonne; 588p.

[5] Cavulli F. L'insediamento di KHB-1 (Ra's al-Khabbah, Sultanato dell'Oman): Lo scavo, i resti strutturali e i confronti etnografici. Ocnus 2004; 12: 37-48.

[6] Salvatori S. The prehistoric graveyard of Ra's al-Hamra 5, Muscat, Sultanate of Oman. J Oman Studies 2007:14.

[7] Charlier P, Georges P, Bouchet F, Huynh-Charlier I, Carlier R, Mazel V, et al. The microscopic (optical and SEM) examination of putrefaction fluid deposits (PFD) potential interest in forensic anthropology. Virchows Archiv 2008; 453: 377-86.

[8] Bernimoulin JP. Recent concepts in plaque formation. J Clin Periodontol 2003; 30(Suppl. 5): 7-9.

[9] Theilade J, Fejerkov O, Horsted M. A transmission electron microscopic study of 7-day old bacterial plaque in human tooth fissures. Arch Oral Biol 1976;10:587-98. 
[10] Tan BT, Mordan NJ, Embleton J. Study of bacterial viability within human supragingival dental calculus. J Periodontol 2004; 75: 23-9.

[11] Howell A, Rizzo A, Paul F. Cultivable bacteria in developing and mature human dental calculus. Arch Oral Biol 1965; 2: 307-13.

[12] McDougall WA. Analytical transmission electron microscopy of the distribution of elements in human supragingival dental calculus. Arch Oral Biol 1985; 8: 603-8.

[13] Jin Y, Yip HK. Supragingival calculus: formation and control. Crit Rev Oral Biol Med 2002; 13: 426-41.

[14] Galgut PN, Mordan N, Newman HN. A transmission electron microscopy study of supragingival calculus. J Int Acad Periodontol 2001; 3: 31-7.

[15] Roberts-Harry EA, Clerehugh V, Shore RC. Morphology and elemental composition of subgingival calculus in two ethnic groups. J Periodontol 2000; 71:1401-11.

[16] White DJ. Dental calculus: recent insights into occurrence, formation, prevention, removal and oral health effects of supragingival and subgingival deposits. Eur J Oral Sci 1997;5:508-22.

[17] White DJ. Recent advances in methods for the assessment of dental calculus research and clinical implications. Monogr Oral Sci 2000;17:163-73.

[18] Middleton WD, Rovner I. Extraction of oral phytoliths from herbivore dental calculus. J Archaeol Sci 1994; 4: 469-73.

[19] Trinkaus E, Marks AE, Brugal JP. Later Middle Pleistocene human remains from the Almonda Karstic system, Torres Novas, Portugal. J Hum Evol 2003; 45: 219-26.

[20] Vandermeersch B, Arensburg B, Tillier AM. Middle Paleolithic dental bacteria from Kebara, Israël. C R Acad Sci Paris 1994; 319: 727-31.

[21] Linossier A, Gajardo M, Olavarria J. Paleomicrobiological study in dental calculus: Streptococcus mutans. Scanning Microsc 1996; 10:1005-13.

[22] Y'Edynak G. Yugoslav mesolithic dental reduction. Am J Phys Anthropol 1989; 78: 17-36.

[23] Hojgaard K. Dentition on Bahrain 2000 BC. Scand J Dent Res 1980; 88: 467-475.

[24] Hojgaard K. Dentition on Umm an-Nar (Trucial Oman), 2500 BC. Scand J Dent Res 1980; 88: 355-64.

[25] Lukacs JR. Dental paleopathology and agricultural intensification in South Asia: new evidence from Bronze Age Harappa. Am J Phys Anthropol 1982;87:133-50.

[26] Littleton J, Frohlich B. Fish-eaters and farmers: dental pathology in the Arabic Gulf. Am J Phys Anthropol 1993; 92: 427-47.

[27] Gualandi PB. Food habits and dental disease in an iron-age population. Anthropol Anz 1992; 50: 67-82.

[28] Djuric Srejic M. Dental paleopathology in a Serbian medieval population. Anthropol Anz 2001; 59: 113-22. 
[29] Torok K, Pap I, Jozsa L. Microscopic study of dental calculus in cadavers from the 18th19th centuries. Fogor v Sz 1999; 92: 317-27.

[30] Macchiarelli R. Prehistoric "fish-eaters" along the eastern Arabian coasts: dental variation, morphology and oral health in the Ra's al-Hamra community (Qurum, Sultanate of Oman, 5 Millennia B. Am J Phys Anthropol 1989; 78: 575-94.

[31] Cavulli F, Scaruffi S. Stone vessels from KHB-1, Ja'lan region, Sultanate of Oman. Proc Seminars Arab Stud 2008; 38: 89-92.

[32] Charlier P, Brun L. A medieval endemic parasitosis. Ann Pathol 2010: 341.

[33] Charlier P, Poupon J, Huynh-Charlier I, Saliège JF, Favier D, Keyser C, et al. Fatal alchemy a gold poisonous elixir in the French 16th court. BMJ 2009; 339: 1402-3. 
Charlier P., Huynh-Charlier I., MunOz O., Billard M., Brun L., LORIN DE la Grandmaison G.

\section{Tables and figures}

Table 1 : Characteristics of DCD matrix and anthropological data for the samples from Monterenzio Vecchia (Bologna, Italy).

\begin{tabular}{|c|c|c|c|c|}
\hline Subject & Sex & Age & DCD matrix & Other DCD characteristics \\
\hline MV 7 & Female & $>45$ & Calcium phosphate & $\begin{array}{l}\text { Crystals of quartz (silicon and oxygen) } \\
\text { Fungal elements }\end{array}$ \\
\hline MV 15 & Male & $25-45$ & Calcium phosphate & $\begin{array}{l}\text { Fibrillar aspect } \\
\text { Crystals of quartz and alumino-silicate } \\
\text { Numerous vegetable formations }\end{array}$ \\
\hline MV 20 & Female & $>45$ & Calcium phosphate & Crystals of quartz and manganese \\
\hline MV 21 & Female & $>45$ & Alumino-silicate & $\begin{array}{l}\text { Crystals of alumino-silicate } \\
\text { Numerous fungal elements }\end{array}$ \\
\hline MV 31 & Female & $>45$ & Alumino-silicate & $\begin{array}{l}\text { Numerous vegetable fibers, red blood cells and grains of } \\
\text { starch } \\
\text { Some fungal filaments } \\
\text { Carbonaceous, magnesium and sulfur impurities } \\
\text { Some quartz crystals }\end{array}$ \\
\hline
\end{tabular}



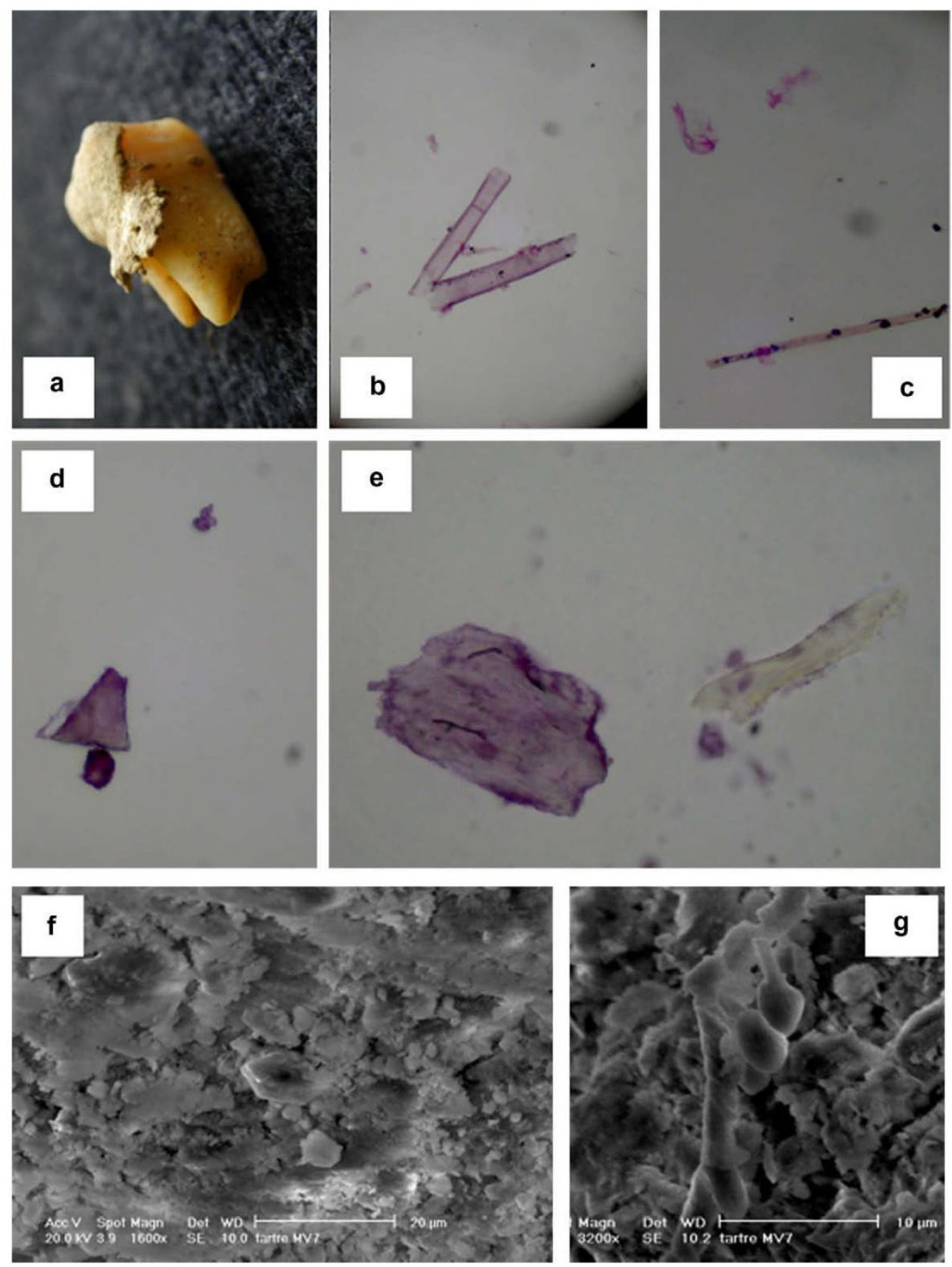

Figure 1: (a) Dental calculus on a molar of the subject MV15 (Etruscan-Celtic necropolis of Monterenzio Vecchia, Bologna, Italy); (b and c) vegetal structures and Malpighian epithelial cells from the DCD of the subject KHB-1 (grave 1, US 169) after cytocentrifugation (HES coloration); (d) crystal structures from the DCD of the subject RH-5 (grave 405, individual B) after cytocentrifugation (HES coloration); (e) Vegetal fibers and crystal structure from the DCD of the subject RH-5 (grave 405, individual B) after cytocentrifugation (HES coloration) and (f) quartz crystal present in the DCD of the subject MV 7 (SEM: enlargement $x$ 1600) and (g) fungal filaments with spores present in the DCD of the subject MV 7 (MEB, enlargement x 3200). 

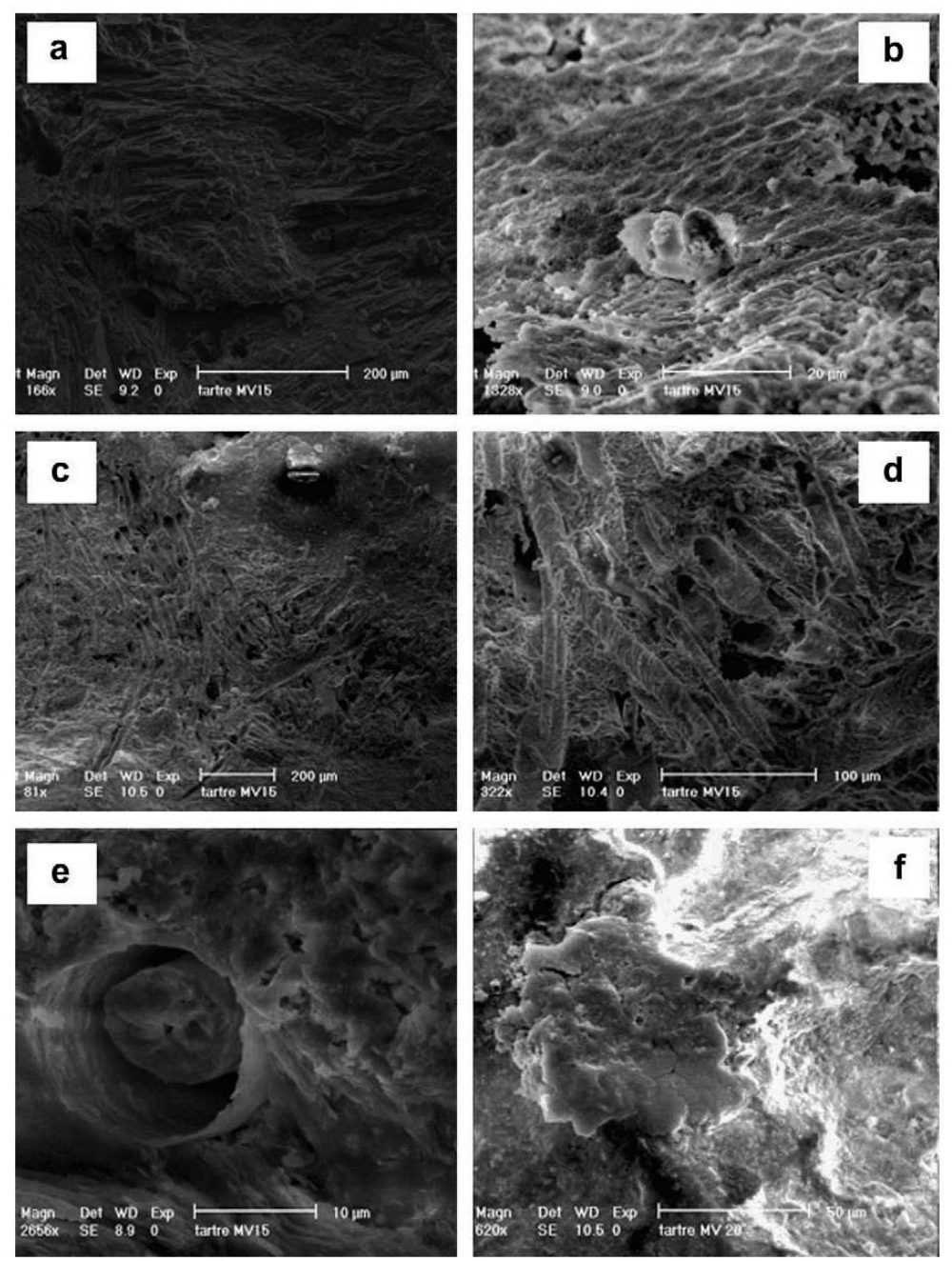

Figure 2: (a) Fibrillary aspect of the surface of the DCD of the subject MV 15 (MEB, enlargement x 160); (b) inner surface of the DCD carrying out a moulding of enamel at the subject MV 15 (MEB, enlargement $x$ 1300); (c-e) details of the vegetable structures enchased in the DCD of the subject MV 15 (MEB, enlargement from _ 80 to 2700 ) and (f) formation rich in manganese (of food origin?) in the DCD of the subject MV 20 (MEB, enlargement $x$ 520).

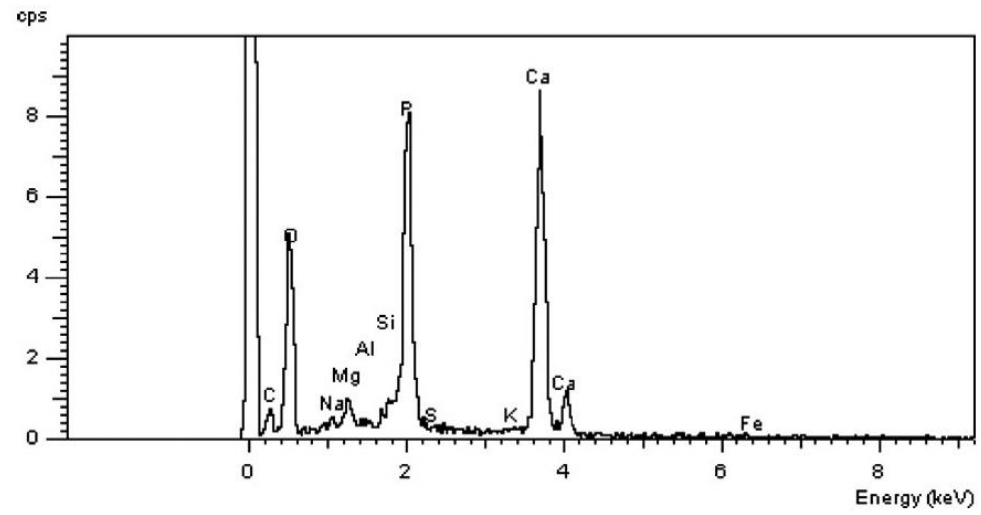

Figure 3: Elemental spectrum of the DCD matrix of the subject MV 15. 

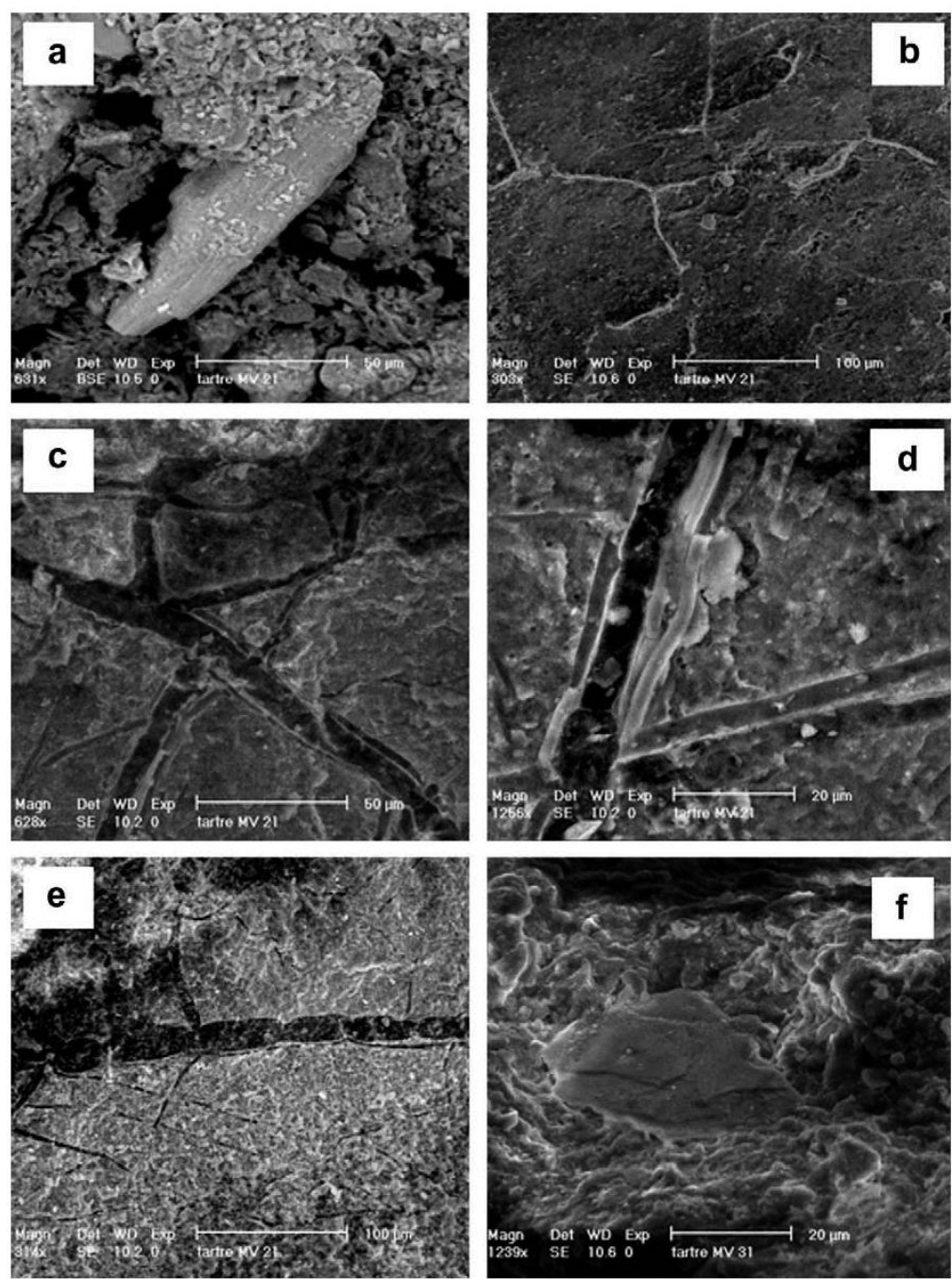

Figure 4: (a) Crystal enchased in the DCD of the subject MV 21 (MEB, enlargement $x$ 630); (b-e) prints of the fungal filaments in the DCD of the subject MV 21 (MEB, enlargement from x 300 to x 1250) and (f) quartz crystal enchased in the DCD of the subject MV 31 (MEB, enlargement x 1240).

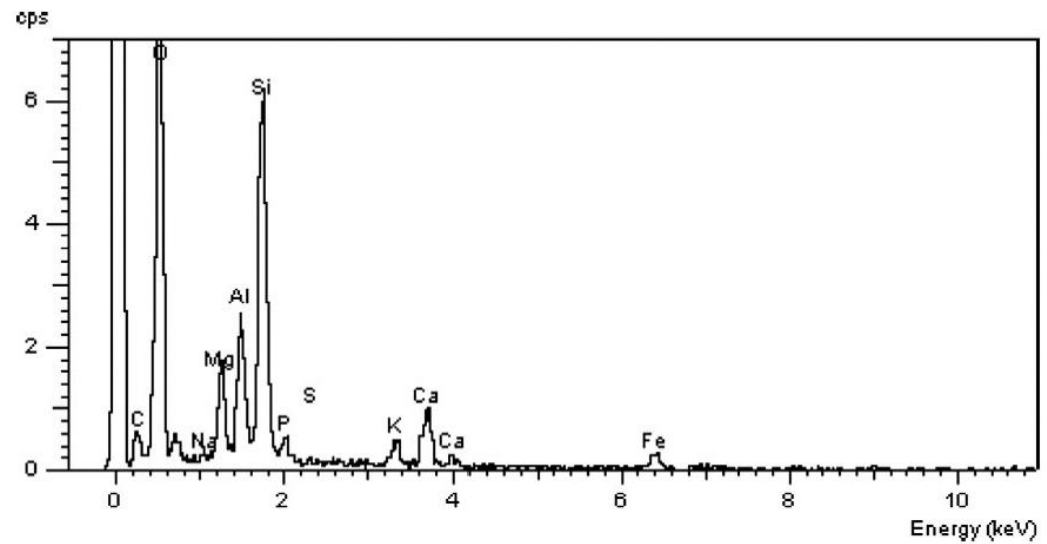

Figure 5: Elemental spectrum of the DCD matrix of the subject MV 31. 

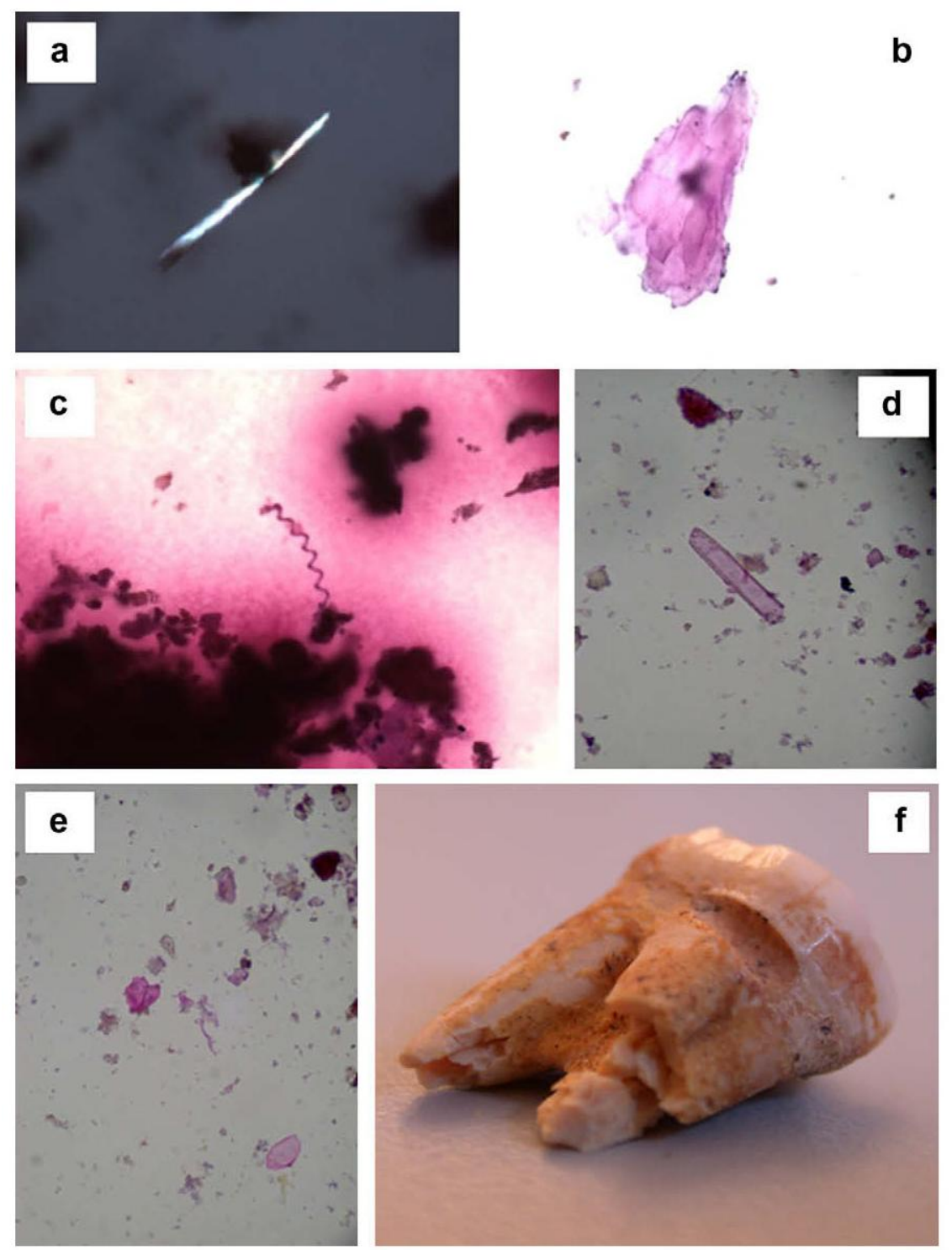

Figure 6: (a) Vegetable fiber from the DCD of a canine of Agnes Sorel observed in OM under polarized light, with a characteristic refringence; (b) group of malpighian epithelial cells from the DCD of a canine of Agnès Sorel after cytocentrifugation (HES coloration); (c) a bacteria of spirochete type from the DCD of a canine of Agnès Sorel after cytocentrifugation (Gram coloration); (d) vegetal fibers from the DCD of Pierre Hazard after cytocentrifugation (HES coloration); (e) crystals and Malpighian epithelial cells from the DCD of Pierre Hazard after cytocentrifugation (HES coloration) and (f) interproximal notch in the right second upper molar of the subject RH-5 (grave 405, individual B). 